\title{
Affective Responses Of Overseas Student-Teachers
}

\author{
Michael W. Firmin, (E-mail: Firmin@cedarville.edu), Cedarville University
}

Ruth L. Firmin, Cedarville University

Brenda B. MacKay, Cedarville University

\begin{abstract}
Universities offering teacher education degrees are finding the world to be significantly smaller than did previous generations. Increasingly, American students are completing their required student teaching in foreign contexts. The present research study used rigorous qualitative methods in order to appraise the affective experiences from a sample of 13 students who completed their student teaching overseas. Results showed, affectively, students experienced a bell-shaped curve phenomenon. Particularly, they underwent stages of excitement when entering the teaching experience, followed by significant dysphoria, and then completed their student teaching with a positive emotional set.
\end{abstract}

\section{INTRODUCTION}

$\mathrm{n}$ the world of education, the tradition of student teaching has become a rite-of-passage. Students preparing to become teachers engage in observing, learning, and applying the knowledge, in actual classroom settings, that they have acquired via college classroom milieu. During the internship-likeexperience, student teachers are expected not only to engage in observational learning, but also to begin developing their own skills as teachers. This involves activities such as grading, preparing lesson plans, and learning to instruct students in the actual classroom. Naturally, these novice student-teachers lack the experience necessary to instruct well, so the student teaching experience provides a supervised and nurturing environment in which the studentteachers can experiment and grow. This also serves as a key stepping stone and a transitioning point, as the studentteachers themselves change from students to teachers.

Given that this is the student-teachers' first experience at teaching in an actual classroom setting, it is not surprising that they face many challenges. Most often, these individuals are undergoing their own developmental life transitions into adulthood (Foos \& Clark, 2003), compounding the stress of added life responsibility. The transition also is a difficult one for student-teachers, since it is their first exposure of having responsibility for others' lives in the classroom. Moreover, as Davis and Mello (2003) indicate, these difficulties are compounded when students participate in overseas student-teaching programs.

To further explore how participating in a cross-cultural endeavor affects student-teachers' experiences, Stachowski and Visconti (1997) compared student-teachers who completed these supervised requirements in the United States with those who taught in foreign countries. As expected, student teachers who taught overseas faced greater obstacles, both quantitatively and in feeling adequately prepared to combat these challenges. Additionally, when determining to what degree challenges had been anticipated, student-teachers participating in overseas teaching were found consistently to underestimate the level of difficult problems they were to face. Students frequently reported that, even if a problem fell into the category of "expected challenge," they often failed to realize beforehand to what degree this issue would present itself later as a classroom problem. 
Firmin, Warner, and Lowe (2006) discussed challenges college students faced when adjusting to American culture. They found students to struggle with adjustment, stereotypes, and fitting in. Additionally, students reported feeling isolated by their peers, resulting from a lack of shared experiences. Generally, American students also displayed a lack of interest in foreign cultures, compounding the isolation felt by their peers who viewed American culture as foreign. Student teachers preparing to travel overseas must address these predispositions of being American-centered in their cultural thinking.

To better clarify student teachers' adjustments to foreign milieus, Brislin, Worthey, and Macnab's (2006) construct of "cultural intelligence" proves useful. The concept describes one's ability to rapidly and adeptly acclimate to new environments. Additionally, cultural intelligence also refers to one's ability to address culturallysensitive issues with care and the ability to modify personal behavior accordingly. Together, these two skill-sets aid those in foreign settings best to adapt to the environment in which they are surrounded. Therefore, cultural intelligence may play a key role in the success of student teachers in cross-cultural environments.

Clement and Outlaw (2002) indicated that professors who supervised overseas student teaching played a fundamental role in the overall success of the experience. E-mail became a key tool for communication, and student teachers relied on this contact as they faced unforeseen challenges, completed assignments, and sought advice from their university professors. Consequently, Citron (2005) suggests that supervising teachers' should prepare students, assist them in their "letting go," help students to expect the unexpected, and encourage students to experience the host culture outside of any American cultural influence or stereotypes.

Bryan and Sprague (1997) address a variety of domains in which the overseas internship experience affected student-teachers' future careers as teachers. First, the perspective of potential employers was one of intrigue and interest, along with a tendency to view these teachers as open-minded and versatile. Additionally, $90 \%$ of Bryan and Spargue's participants reported this experience as having been beneficial vis-a-vis future hiring. Second, teachers acknowledged changes in their attitudes toward cultural issues. For example, teachers reported demonstrating a greater respect for individual differences, a greater sensitivity to cultural influence, and a greater feeling of preparation as it related to cultural needs. Teachers also reported their international teaching experience to have positively impacted their teaching flexibility, curriculum choices, retention in teaching, attitudes towards second languages, and teaching strategies.

Stachowski, Richardson, and Henderson (2003) studied the effects of cultural exposure on students, and found the greatest impacts affected teachers' perspectives in the classroom. Teachers not only reported an increased interest in other cultures, but also interest in integrating cross-cultural teaching experiences into their American classrooms. Such activities included them providing opportunities for students to learn more about foreign cultures.

While multiple methods could be used to further explore the construct of overseas student teaching, qualitative methodology seemed most germane at present. It is a common approach for exploratory investigations (Willis, 2007). Further, it is appropriate for studies where little previous research has been conducted and testable quantitative hypotheses are not feasible (Bogdan \& Biklen, 2007). The qualitative method also enabled us to develop some thick descriptions of how student teachers came to understand their worlds. This can become the basis for further research endeavors whereby quantitative research can build on the present findings.

\section{METHOD}

The participating students interviewed for this study attended a selective, private, comprehensive university located in the Midwest United States. The students were enrolled in an education program as part of a licensuretrack degree for teaching in public school settings. During the time frame we were conducting the study, 13 students were scheduled to complete their overseas teaching, and each agreed to participate. Twelve students were female, and one was male. While this ratio is significantly unbalanced, we found it to be somewhat proportional to the gender ratio of students enrolled in the university's education program. Students interviewed were between the ages 21 and 23, and all were graduating seniors. While overseas, each of the participants taught subjects content to international students in English. 
Within two days of the student teachers' return to the university campus, each participated in an in-depth interview. To assess students' perceptions of their involvement overseas, we conducted semi-structured interviews. These involved some common questions regarding their experiences and others that openly explored the participants' percepts regarding their international experiences. This allowed the students to direct the interviews toward areas they (personally) felt were meaningful. Using inductive methodology allowed the participants freely to share stories, experiences, and their perspectives on the overseas teaching experience.

This process involved interviewing all the participants one time (first wave). The research team assessed the transcripts for codes and potential themes. The tentative findings then provided the basis to target particular participants for a second wave of interviews-honing the general percepts to more developed constructs. We conducted two waves of interviews, following the protocol established by Firmin (2006). We tape recorded interviews and later transcribed them for detailed analysis. The names used in the present article obviously are pseudonyms, used for reading clarity and to keep the identity of our participant anonymous.

Maxwell's (2005) system for inductive coding was used to analyze data. The researchers met frequently, using open-coding to assess potential themes that developed during the first wave of interviews. Constantcomparison techniques (Glaser, 1998) were used to assess the transcripts. We used themes found in the first wave of interviews to structure the second wave, providing more specific questions and directing the interviewees to elaborate on themes that previously had emerged. Focusing on specific areas of students' experiences allowed us to flesh-out more detailed descriptions of the phenomenon they previously were describing.

The debate today among qualitative researchers regarding the use of theory in empirical, qualitative research has been well document by Raffanti (2006). Researchers such as Glaser (1992) argue that the use of theory in interpretation will only taint the results of a qualitative research study and, therefore, researchers seeking objective findings should avoid its use. In contrast, those who hold to a more progressive view, support researchers such as Strauss and Corbin (1998), arguing that theory proves useful in interpreting data during varied stages of the research process. While we genuinely respect both positions, philosophically we are committed to the nontheoretical approach to qualitative research (Glaser, 1998). Further, we believe it is the place of the reader to interpret data through the theory of their choice, allowing for data to be analyzed through multiple perspectives (Johnson \& Christen, 2004). Consequently, we deliberately avoided applying theory or any other potentially deductive means of interpretation. Bracketing (Raffanti, 2007) our own biases throughout the analysis and write-up of the article was considered crucial to applying the qualitative research method in its traditional form. That is, our goal was to provide findings atheoretically, being as objective as we humanly could, apart from philosophical or theoretical interpretations.

After completing the coding process, initial themes that had emerged were discarded due to a lack of plenary support. As a result, the findings of this study have been limited to those that are reflective of the majority of our participants. Our research team also met regularly to help ensure internal validity, which included eliminating themes that were not unanimously decided to be representative of our participants as a whole. Our findings reached a point of saturation (Guest, Bunce, \& Johnson, 2006), meaning that we found the students generally to be repeating the same general themes. We believe that had further interviews been conducted, the law of diminishing returns would come into effect, which bolstered our confidence in the sample size used for the present study (Daytner, 2006). Member checks (Charmaz, 2006) were applied following the study's competition. Each of the participants consulted, regarding the themes generated, were in substantial agreement that our results represented their views. Internal validity also was achieved generating a data trail (Silverman, 2005). And finally, internal validity also was enhanced through outsider assessment (Hesse-Biber \& Leavy, 2006). Having an individual, independent of the original data analysis, confirm the direction of our findings, aptly grounded in the participants' transcripts, also helped to provide confidence in the accuracy of our reported results. 


\section{RESULTS}

From the data set, we previously have presented findings on both the intrinsic and the extrinsic factors that affect student teachers' international experiences (Firmin, MacKay, \& Firmin, 2006; Firmin, MacKay, \& Firmin, 2007). Intrinsic factors included aspects such as cultural differences, fitting-in, and social support, while extrinsic factors encompassed areas such as language adjustment, preparation issues, and distance supervision. Following this research, an additional theme, reported here, involved the students' affective responses to their international experiences. A bell shaped curve phenomenon became evident when reading carefully through the tape recorded transcripts. By this, we mean that students underwent a three-stage emotional cycle, beginning with a state of excitement (including anticipatory nervousness). Next, at the curve's peak, students experience a state of dysphoria, in which discouragement and other negative emotions were reported. Ultimately, the student teachers returned to more positive emotional states, in which they genuinely enjoyed their experiences. Inevitably, this phase was disrupted by the emotional responses associated with the difficulties of leaving in order to return home to the U.S. Vanessa articulately summarized the process that most students underwent as she described the emotional aspect of her overseas experience:

You're really excited at first, and then you go through the stage of "I don't like this anymore." Nothing seems fun anymore and everything is different. And then you start to like it again. And I remember that they told us right when you're really liking it, then you leave, and it's defiantly how I felt. Like, I wasn't ready at all to come home. Like, I would call the same people at home if I had to say goodbye there.

Based on the testimonies of our participants, we propose that the three stages are experienced in order, but for varying lengths of time, depending on the student teachers' general temperaments and personal experiences while overseas. Additionally, each student may not necessarily experience the emotions of each stage with the same intensity, again taking into account personal and situational factors.

\section{Excitement/Anticipatory Nervousness}

This first emotional state encompassed a positive spectrum of emotions, together with anticipatory nervousness, as the students contemplated the unknown. Because our participants were traveling to foreign countries, they faced greater unknowns than those students completing their student-teaching in the United States. Consequently, students teaching overseas had more to anticipate, as participants looked forward to unique international experiences. However, this greater unknown also served as a greater cause for worry. While students prepared themselves to the best of their abilities, anticipatory anxiety, to some extent, was an inevitable, yet healthy part of their emotional process. Student-teachers reported that a primary cause for worry was not being able to anticipate the type of setting in which they would be living or teaching. Willa globally summarized: "Um, I was nervous going down just because I didn't know what to expect at the school." We found the student teachers' apprehension to be compounded by cultural dynamics present in their overseas classrooms. As Tabitha shared, having a dynamic such as language confusion only added to the anticipatory nervousness she was already experiencing:

I was already nervous beginning teaching in a new school, but having a language barrier where for most of my students, English is not their first language...I would get very nervous, and I would stop talking because I didn't want to embarrass them more, or I felt very foolish, and it took me a few weeks to finally understand their accent.

Despite the students' nervousness, overall, they were eager to begin their overseas teaching experience and expressed a range of positive emotions. Furthermore, as participants anticipated their student-teaching, they predicted what particular dynamics of their experience would be like, emphasizing the aspects to which they were most looking forward. For example, Lara remembered predicting: "As far as the teaching, like I was really looking forward to the students, and I thought that would be really fun because to me they all have accents and to them I did." 


\section{Dysphoria}

Following the bell shaped curve pattern, student teachers' excitement was followed by a diverse range of negative emotions. While they fought to keep it from affecting their teaching, these negative emotions did take a toll on our participants. Karena adeptly described how going through this difficult phase emotionally affected her: "Um, I think, that especially at the beginning, that there was so much change and so many things to be adjusted to, especially in the beginning - it was very emotionally draining, just king of making myself do things that were either scary or I didn't want to do or wasn't sure how to do."

Our student teachers also reported that language barriers were sources of frustration or anxiety, inside and outside of the classroom. To illustrate, Tonia shared her story:

At first there was very much the feeling of being overwhelmed, especially the first maybe three weeks, because I didn't know any Spanish. I was living with a Mexican woman and so she spoke some English-she spoke more English than I did Spanish - and so our conversations at first were very broken in trying to understand what exactly she was asking me. And even in school it was, I felt very intimidated because I realized that I was wondering if my students realized that I didn't know Spanish and if they would try to take advantage of that in any way. And so at first it was very overwhelming.

Especially outside of the classroom, where they had to either learn the foreign language themselves or use a translator, student teachers soon realized the many frustrations that accompany a language barrier. Tabitha illustrated, describing how this affected her socializing: "I don't know if I was necessarily disappointed, but I became discouraged at points - speaking through translation gets really tiring too fast, and especially when we'd hang out for hours at a time, and I would wish I knew more.” Additionally, Rae shared how, because of her frustration, she eventually relinquished her attempt to understand the language:

Well, at first I really tried to understand what was going on, but it definitely strains you, like your energy, so like by the end I kind of got lazy and I relied on other people...I realize that I know I guess I was frustrated that I couldn't understand them and I wished that I knew more Spanish to be able to communicate with them, but that wasn't my case, so I had to rely on others to help me.

While not all students from our sample experienced the emotions related with homesickness, a significant portion of the student teachers did combat these feelings. As Rosalie explained, homesickness often was the result of not feeling a sense of acceptance or belonging to this foreign environment and culture. Karena shared her strategies to keep feelings of homesickness from ruining her experience:

I would see something that one of my family members would really enjoy; like, oh I wish that they could see this! And I don't know if it affected my teaching, but there were definitely days when it was hard to go to school just because I would rather sit in my room and mope. But getting out of my room did, and having school, did keep my busy, definitely help keep my mind occupied. If I was at home and I started getting lonely, then there was normally almost always something at school that needed to be done, whether it be grading or planning or things like that.

Participants also expressed frustrations similar to those commonly reported by student-teachers in the United States, showing that while the international involvement is a completely unique experience, all student teachers must learn to deal with adjustment issues. Tabitha elaborated as she described dealing for the first time with classroom planning and responsibility:

I think the feeling of never being on top of things. I am always having grading, I am always creating lesson plans, and I always have that plan of accomplishment. Well, I don't feel that too often because you're always continual, and I had to learn to deal with that emotion, to not meeting that accomplishment, but there are little accomplishments along the way, and just to keep going at it, and not to get frustrated that I would have to keep working, but to enjoy that responsibility. 
In addition to the "normal" adjustments that student-teachers are required to make, those teaching overseas additionally must learn to teach in a manner that is appropriate for the cultural needs of their classroom. Justine continued this idea, as she contrasted her field experiences in the United States to that of her overseas classroom: "I think it was much easier to get frustrated quickly...I felt the way that I taught in my field experiences in the States, were very different from the way that I taught in Costa Rica."

Finally, student teachers reported missing elements of American culture, and found themselves longing for these seemingly "basic" elements to which they had been accustomed. While acknowledging that most of these matters were insignificant in the overall scheme of their international experience, the student-teachers struggled not to let these "little" changes to become overwhelming or to become overly homesick. To explain, Vanessa shared:

Well, it's going to sound silly, but those things that you do every day, like I had to take a bath every day-there was no shower, and that was really annoying to me. I got used to it eventually [but] I really, really didn't like that at first. And the bathroom sink! The hot and the cold water separated so if you wanted to wash your face, you either have to use really, really hot water or really, really cold water and you can't really mix them in your hands because that really won't work, so I had to learn to wash my face with really cold water. I didn't have a dryer so I had to always hang my clothes about. It was just the little things like that that you do all the time that I missed.

\section{Enjoyment}

At some point, the student-teachers' emotions regarding their experience transitioned from dysphoric to enjoyment. As they learned to handle correctly their negative emotions, the student teachers were awakened to the positive aspects of their experiences that previously had been overlooked or under-appreciated. To illustrate, Tabitha described her experience in this regards:

Because I was a new teacher, and I was foreign and I couldn't understand the talking, and I was getting really discouraged, and I didn't like teaching, I didn't like facing that. But as we spent more time together and began to understand their language, and began to understand their culture, then I became fascinated with their culture, and the reasons for why they talk the way they talk and do the things they do.

Student teachers, at first, generally were hesitant to venture emotional connections with those in their foreign milieus. They reasoned that these relationships and experiences inevitably would come to an end, thus, avoiding them altogether would help in skirting any potential pain involved in leaving. However, it was not long before these student teachers realized to what extent they had limited their enjoyment of the overseas teaching. As Phoebe recognized, making emotional connections with her new acquaintances and students greatly added to her satisfaction of the overall experience: "At first, it was really had for me to get involved with the kids and teaching and things like that because I was already lonely and was like I'm going to be leaving anyway, so "why get attached?' kind of thing. But about two weeks into it, I was very excited about what I was doing and so it kind of pushed the motive and getting to do everything." All humans, to vary degrees, are social beings. The studentteachers in our study came to realize this life fact, letting down their defenses, and connecting more freely in relationship-building.

As we studied the transition of students from negative to positive emotional states, we found a variety of factors that initiated this change within the student teachers. For students like Karena, coping with stressors, such as new environments or foreign languages, kept them from initially enjoying their experiences in a plenary manner. Consequently, when these elements of stress were reduced (simply with the passage of time or through normal, coping adjustment) they were able to feel more comfortable and finally able to revel their experience. Karena commented: "I really enjoyed living there, once I got learning some Spanish and to know some people and to know my way around." Other dynamics that inhibited students' enjoyment of their experiences related to their adjustments as novice teachers. Being inexperienced, the student teachers found themselves constantly learning and adjusting to the realities of teaching. An interesting association emerged from the student teachers' testimonies: as their teaching abilities developed, the stress contributing to their negative emotions decreased. Tabitha described her progression: 
I think the whole balance of teaching, just learning to do lesson plans, learning to reflect, learning to talk to other teachers for ideas. At first, I felt very overwhelmed, trying to juggle it all, and it wasn't. By the end, it kind of almost got to a pattern or a rhythm. I wasn't quite there, but it wasn't as frustrating or as overwhelming, but I feel like I actually had a handle on it to a degree.

Olga further described the positive emotions that accompanied learning as a teacher which, for her, involved finding the appropriate balance: "I think I got more comfortable, more confident, but also learned...to let things go a little bit more so I could get the right balance and not overwhelm myself." In sum, student teachers found that the initial stress of their cross-cultural experience, in various forms, had the ability to divert them from fully enjoying their overseas teaching.

However, students in time were able to effectively take steps to manage stress, allowing them eventually to enjoy their international teaching experiences. Our participants eagerly shared instance after instance, describing specific elements of their trip that they enjoyed. As Vanessa recounted: "I loved my students and we defiantly had fun! Like they would be asking me all of these cultural questions, and I liked chatting with them. And that was something that I thought would be great, and it was!" Student teachers also reported that enjoying their experience enhanced their teaching abilities, as these positive emotions bolstered their confidence and the excitement that they were able to bring into the classroom. For Olga this included enjoying not only her teaching environment, but also relationships with her students: "I had a good rapport with my students, many of them were my friends, and I was happy. And it makes it easier to teach when you like being there, and when you enjoy teaching and when you feel emotionally satisfied."

\section{Difficult Leaving}

As students shared their sentiments about returning to the United States, they admitted that initially they had anticipated being emotionally ready to return home when their teaching ended. In actuality, however, participants' reactions were the converse of their expectations. To explain, Tabitha described:

Well, I really did picture it as something I could just trudge through and get through, and be so happy when it was over-and it was pretty much the opposite. I really enjoyed teaching and I really enjoyed my students, and I was pretty sad when it was over, and I was expected to leave.

Overall, student teachers were pleased with their international teaching experiences and expressed poignant responses about leaving their host country. Maddie, representing many student-teachers in our sample, expressed significant satisfaction with her experience, specifically adding that overall she was not left disappointed on any level. Bruce vocalized thusly the student teachers' reluctance in leaving their overseas environments: "I think that when I left I was surprised at how there were so many things that I knew I would miss once I left." Finally, as the student-teachers were struck with the reality of their nearing departure, they prepared themselves emotionally. This included saying goodbyes, last minute concluding activities, and extra emotional extensions to those around them. Karena best summarized the student-teachers' efforts in dealing with their departures:

Before I left, I stared kind of realizing that my time was coming to a close and wanting to do everything that I wanted to do and making sure that I had done everything at school and kind of soaking up those few weeks with my students, knowing that I wanted to invest in their lives as that time was coming to a close...So all those emotions kind of came at the end as time was running out, knowing that time was running out, and knowing that there were a lot of things I wanted to do or say.

\section{LIMITATIONS AND FUTURE RESEARCH}

The sample used in the present study included all Caucasian student teachers. There were no efforts to delimit the sample from minorities. Rather, this simply was a reflection of the individuals who completed their student teaching overseas during the semester we collected data. Further studies should explore the experiences of minority individuals and compare the findings with the present research study. 
Most of the students in the sample were females. Again, there was no attempt to exclude college men from the study. The population of students at the university where the study was conducted included a large proportion of males in the teacher education program and the sample demographics reflect this phenomenon. Further research should concentrate on the experiences that male student-teachers report and compare them with the findings from the present study.

As with all qualitative research studies, external validity is always a limitation. While we believe that the results aptly reflect the perceptions of the individuals studied, generalizing the results to all student-teachers is not possible. Nonetheless, the results from the present research should be used heuristically in order to provide foundations for further quantitative projects, including surveys using large samples, whereby external validity from the present findings might be strengthened.

\section{REFERENCES}

1. Bogdan, R., \& Biklen, S. (2007). Qualitative research methods $5^{\text {th }}$ ed. Boston: Allyn \& Bacon.

2. Brislin, R., Worthley, R., \& MacNab, B. (2006). Cultural intelligence: Understanding behaviors that serve people's goals. Group \& Organization Management, 31, 40-55.

3. Bryan, S. L., \& Sprague, M. M. (1997). The effect of overseas internships on early teaching experiences. The Clearing House, 70, 199-201.

4. Charmaz, K. (2006). Constructing grounded theory. Thousand Oaks, CA: Sage.

5. $\quad$ Citron, J. (2005). Dr. Jim's tips for directors of U.S. students abroad. International Educator, 14, 64-66.

6. Clement, M. C., \& Outlaw, M. E. (2002). Student teaching abroad: Learning about teaching, culture, and self. Kappa Delta Pi Record, 38,180-183.

7. Davis, P. W., Mello, N. A. (2003). Beyond study abroad: The value of international experiential education, International Educator, 12, 40-48.

8. Daytner, K. (2006, June). Validity in qualitative research: Application of safeguards. Paper presented at the $18^{\text {th }}$ Annual Ethnographic and Qualitative Research in Education Conference, Cedarville, OH.

9. Firmin, M. (2006). Using interview waves in qualitative phenomenological research. In P. Brewer \& M. Firmin (Eds.). Ethnographic \& qualitative research in education. New Castle, UK: Cambridge Scholars Press.

10. Firmin, M., MacKay, B., \& Firmin, R. (In Press). Intrinsic factors affecting overseas student teaching. Education.

11. Firmin, M., MacKay, B., \& Firmin, R. (In Press). Extrinsic factors affecting overseas student teaching. Journal of Ethnographic \& Qualitative Research.

12. Firmin, M., Warner, S., \& Lowe, A. (2006). Social adjustment among students growing up in foreign missionfield contexts. Christian Higher Education, 5, 115-124.

13. Foos, P. W., \& Clark, M. C. (2003). Human aging. Boston: Allyn \& Bacon.

14. Glaser, B. G. (1992). Basics of grounded theory analysis. Mill Valley, CA: Sociology Press.

15. Glaser, B. G. (1998). Doing grounded theory: Issues and discussions. Mill Valley: Sociology Press.

16. Guest, G., Bunce, A., Johnson, L. (2006). How many interviews are enough? An experiment with data saturation and variability. Field Methods, 18, 59-82.

17. Hesse-Biber, S., \& Leavy, P. (2006). The practice of qualitative research. Thousand Oaks, CA: Sage.

18. Johnson, B., \& Christensen, L. (2004). Educational research $2^{\text {nd }}$ ed. Boston: Allyn \& Bacon.

19. Maxwell, J. A. (2005). Qualitative research design. $2^{\text {nd }}$ ed. Thousand Oaks, CA: Sage.

20. Raffanti, M. (2006). Grounded theory in educational research: Exploring the concept of groundedness. In In M. Firmin \& P. Brewer (Eds.), Ethnographic and Qualitative Research in Education, Vol 2. (pp. 62-74). Newcastle, UK: Cambridge Scholars Press.

21. Raffanti, M. (2007). Phenomenological bracketing as a pedagogical took in grounded theory. Paper presented at the $19^{\text {th }}$ annual Ethnographic \& Qualitative Research in Education conference, Cedarville, $\mathrm{OH}$.

22. Silverman, D. (2005). Doing qualitative research $2^{\text {nd }}$ ed. Thousand Oaks, CA: Sage.

23. Stachowski, L., Richardson, J., \& Henderson, M. (2003). Student teachers report on the influence of cultural values on classroom practice and community involvement: Perspectives from the Navajo reservation and from abroad. The Teacher Educator, 39, 52-63.

24. Stachowski, L.L., \& Visconti, V. (1997). Adaptations for success: U.S. student teachers living and teaching abroad. International Education, 26, 5-20.

25. Strauss, A. L., \& Corbin, J. (1998). Basics of qualitative research: Grounded theory procedures and techniques. Newbury Park, CA: Sage.

26. Willis, J. W. (2007). Foundations of qualitative research. Thousand Oaks, CA: Sage. 